\title{
Oligodendroglioma, Not Otherwise Specified
}

National Cancer Institute

\section{Source}

National Cancer Institute. Oligodendroglioma, Not Otherwise Specified. NCI Thesaurus.

Code C129319.

An oligodendrog lioma in which there is insufficient information on the IDH genes and $1 p / 19 q$ codeletion status. 